\title{
Increased apoptosis of lactotrophs in streptozotocin-induced diabetic rats is followed by increased proliferation
}

\author{
Ana I Arroba, Alfonso M Lechuga-Sancho, Laura M Frago, Jesús Argente and Julie A Chowen \\ Department of Endocrinology, Hospital Infantil Universitario Niño Jesús, Universidad Autónoma de Madrid, Madrid, Spain \\ (Requests for offprints should be addressed to J A Chowen who is now at Departamento de Endocrinología, Hospital Infantil Universitario Niño Jesús, \\ Avenida Menéndez Pelayo, 65, 28009 Madrid, Spain; Email: jachowen@telefonica.net)
}

\begin{abstract}
Poorly controlled diabetes mellitus can result in decreased prolactin production and thus problems with lactation, reproduction, and other physiological processes. This may be due to a loss of lactotrophs, as we have previously shown that long-term (8 weeks) poorly controlled streptozotocininduced diabetes results in increased death of lactotrophs and that this most likely occurs through the activation of caspase- 8 and the extrinsic cell death cascade. However, cell proliferation is also increased in the anterior pituitary at this time, although the cell type undergoing this proliferation and whether it is a response to the increased cell death remains unknown. In order to determine the time-course of increased cell death and proliferation in the anterior pituitary and if this is related to changes in tumor necrosis factor (TNF)- $\alpha$, a cytokine involved in the activation of the extrinsic cell death
\end{abstract}

pathway, rats were killed at $1,4,6$, and 8 weeks after the induction of diabetes. Cell death was significantly increased after 4 weeks, as was caspase- 8 activation, although circulating levels of TNF- $\alpha$ were increased as early as 1 week. Pituitary levels of TNF- $\alpha$ did not change significantly until 8 weeks after diabetes onset. Similarly, Western-blot analysis of proliferating cell nuclear antigen showed that anterior pituitary cell proliferation increased significantly 8 weeks after diabetes onset, with the majority of proliferating cells, as detected by BrdU incorporation, corresponding to lactotrophs. These results suggest that the increased death of lactotrophs in poorly controlled diabetic rats is followed by increased proliferation of this cell type, even when no treatment is given.

Journal of Endocrinology (2006) 191, 55-63

\section{Introduction}

It is well known that prolactin is important for lactation and reproductive functions; however, it is also involved in the regulation of growth, development and metabolism, electrolyte balance, immune responses, behavior, and stress responses (Bole-Feysot et al. 1998). Hence, modifications in prolactin secretion may have wide-ranging effects in both males and females. Circulating prolactin levels have been shown to be reduced in poorly controlled diabetes mellitus (Ikawa et al. 1992. Montelongo et al. 1992, Ostrom \& Ferris 1993, Valimaki et al. 1991) and diabetes can result in reduced lactating capabilities in both women and experimental animals (Ikawa et al. 1992, Lau et al. 1993, Ostrom \& Ferris 1993, Neville \& Morton 2001). In addition, decreased prolactin levels in diabetic animals have been associated with steroidogenic defects (Sudha et al. 1999) and a decreased stress response (Ratner et al. 1991), including the response to hypoglycemia (Kinsley et al. 1996).

We have previously demonstrated that there is a reduction in the number of lactotrophs in the rat pituitary after 8 weeks of poorly controlled diabetes (Arroba et al. 2003), which could explain the decrease in circulating prolactin levels in these animals. This loss of lactotrophs is due, at least in part, to increased apoptosis of this cell type involving activation of caspase-8 (Arroba et al. 2005). Caspase- 8 is the prototypical caspase of the extrinsic or death receptor pathway of apoptosis that is activated by an extracellular insult or ligand binding to members of the tumor necrosis factor (TNF)- $\alpha$ receptor superfamily (Boldin et al. 1996, Wajant 2002). Indeed, circulating TNF- $\alpha$ levels are reported to be elevated in diabetic patients, as well as in streptozotocin-induced diabetic rats (El-Seweidy et al. 2002, Jain et al. 2002), and this cytokine is implicated in apoptosis during diabetes (Chen \& Goeddel 2002) and in lactotrophs (Candolfi et al. 2002), suggesting its possible involvement in the loss of this cell type in diabetes.

The number of cells for any specific cell type in a tissue is the result of the balance between proliferation and death. Hence, the reduction in the number of lactotrophs in the anterior pituitary of diabetic rats could also involve a decrease in proliferation. However, at 8 weeks of diabetes, pituitary levels of proliferating cell nuclear antigen (PCNA) are increased (Arroba et al. 2003). It is possible that this increased proliferation is in response to the increased cell death and hence, be specific to the dying cell type or types. Thus, 
the aims of this study were to: (1) determine when programmed cell death begins in the pituitary of rats with poorly controlled diabetes mellitus; (2) associate this increase in cell death with temporal changes in circulating and pituitary TNF- $\alpha$ levels and caspase- 8 activation; and (3) analyze when the increase in cell proliferation begins and determine if lactotrophs are affected.

\section{Materials and Methods}

\section{Materials}

Electrophoresis reagents were from Bio-Rad. All chemicals were purchased from Sigma or Merck unless otherwise noted.

The antibody for prolactin was from the National Hormone and Peptide Program (Cat. No. AFP65191, Torrance, CA, USA). The antibody to caspase- 8 or Fas-associated death domain (FADD)-like ICE/MORT-1-associated Ced3 homologue (FLICE) was purchased from NeoMarkers (Cat. No. RB-1200, Fremont, CA, USA), PCNA from Signet Laboratories (Cat. No. 523-01, Dedham, MA, USA), phosphorylated-histone-H3 (phospho-H3) from Upstate Biologicals (Cat. No. 06-570, Lake Placid, NY, USA), and actin from Santa Cruz Biotechnology (Cat. No. sc-1616, Santa Cruz, CA, USA). BrdU was purchased from Sigma, and the antibody toward BrdU was from DAKO (Cat. No. M0744, Glostrup, Denmark).

\section{Animals}

Adult male Wistar rats were injected (i.p.) with $70 \mathrm{mg} / \mathrm{kg}$ streptozotocin (STZ; Sigma). Control rats received vehicle only. Blood glucose concentrations were measured in the morning via tail puncture (Glucocard Memory 2; Menarini Diagnostic, Florence, Italy) and the animals were considered to be diabetic if they maintained mean glucose levels $>$ $300 \mathrm{mg} / \mathrm{dl}$. The rats were killed in the morning by decapitation at $1,4,6$, and 8 weeks after diabetes onset, and the pituitaries were immediately removed and frozen on dry ice. Trunk blood was collected, allowed to clot, and centrifuged. The serum was separated and stored at $-20{ }^{\circ} \mathrm{C}$. The anterior pituitary was processed for protein extraction as indicated later and the samples were stored at $-80{ }^{\circ} \mathrm{C}$. The rats were treated according to the European Community laws for animal care, and the studies were approved by the ethics committee of the institution. All the experiments were repeated at least twice. In all ELISA and western analyses, four diabetic rats/group and eight control rats were used. In immunohistochemistry studies, three rats per group were used.

The following groups of rats were established: diabetic for 1 week (DB1W), diabetic for 4 weeks (DB4W), diabetic for 6 weeks (DB6W), and diabetic for 8 weeks (DB8W). Control rats were killed at each time-point, but because no differences were found between control rats at the different time-points in any of the studied variables (data not shown), control data were pooled for statistical analysis.

\section{BrdU injection}

In a separate experiment to label proliferating cells, diabetic and control rats were prepared as above and BrdU was injected $(100 \mathrm{mg} / \mathrm{kg}$ per day; i.p.) on the 4 consecutive days prior to killing at 8 weeks after the induction of diabetes $(n=$ 4 per group).

\section{ELISA cell death detection}

This assay was carried out according to the manufacturer's (Cat. No. 1544676, Roche Diagnostics) instructions. Briefly, each anterior pituitary was homogenized in $300 \mu \mathrm{l}$ incubation buffer, placed on ice for $1 \mathrm{~h}$, centrifuged at $1200 \mathrm{~g}$ for $5 \mathrm{~min}$ at $4{ }^{\circ} \mathrm{C}$, and the supernatant collected. Microtiter plates were prepared by adding $100 \mu \mathrm{l}$ coating solution (anti-histone antibody) to each well and incubated for $1 \mathrm{~h}$ at room temperature. The coating solution was removed and $200 \mu \mathrm{l}$ incubation buffer added and incubated for $30 \mathrm{~min}$ at room temperature. The wells were then rinsed twice and the samples $(25 \mu \mathrm{l}$ sample $+75 \mu \mathrm{l}$ buffer) added and incubated for $90 \mathrm{~min}$ at room temperature. After washing, $100 \mu \mathrm{l}$ conjugate solution (anti-DNA-peroxidase) were added and incubated at room temperature for $90 \mathrm{~min}$. After washing, $100 \mu \mathrm{l}$ substrate solution were added and mixed until the color developed adequately (approximately $15 \mathrm{~min}$ ). The samples were measured at $405 \mathrm{~nm}$ on an automatic microplate analyzer (Biotek Instruments, Inc., Winooski, VT, USA). Each sample was measured in duplicate in each assay. Background measurements were made and this value subtracted from the mean value of each sample. Induced cell death in cultured cells (GH3) was used as positive control. This assay had a detection limit of approximately 50 dead cells/well and the results were normalized to protein levels in each sample and are reported as relative levels of cell death compared with controls. The inter- and intra-assay coefficients of variation (CV values), as determined by repeated assay of test samples with low, intermediate and high levels, were 8.5 and $4 \cdot 3 \%$ respectively.

\section{Immunoblotting}

For western blotting, tissue was homogenized on ice in $300 \mu \mathrm{l}$ radio-immunoprecipitation assay buffer (RIPA) lysis buffer with an EDTA-free protease inhibitor cocktail (Roche Diagnostics) and then centrifuged at $12000 \mathrm{~g}$ for $5 \mathrm{~min}$ at $4{ }^{\circ} \mathrm{C}$ to remove the insoluble material. Clear supernatants were transferred to a new tube to measure protein content by using Bio-Rad Laboratories, Inc. protein assay. Protein (30-60 $\mu \mathrm{g}$ ) was resolved using 12\% SDS-PAGE and then transferred onto PVDF membranes (Bio-Rad). Membranes were blocked with Tris-buffered saline containing $5 \%(\mathrm{w} / \mathrm{v})$ nonfat dried milk and incubated with the primary antibody 
at a dilution of 1:1000. Membranes were subsequently washed and incubated with the corresponding secondary antibody conjugated with peroxidase at a dilution of 1:2000 (Pierce, Rockford, IL, USA). Bound peroxidase activity was visualized by chemiluminescence (Perkin-Elmer Life Sciences, Boston, MA, USA) and quantified by densitometry using Bio-1D (Vilber Lourmat, Marne La Vallee, France). For each assay, the results were normalized to control levels and protein-loading variability normalized by rehybridizing the membrane with antibody to actin (Sigma).

\section{TNF- $\alpha$ ELISA}

This assay was carried out according to the manufacturer's (Cat. No. HK102, HyCult Biotechnology b.v., The Netherlands) instructions. Briefly, serum was diluted 1:4 in dilution buffer as recommended by the manufacturer. For pituitary protein extracts (in RIPA as described earlier), samples from each experimental group were diluted 1:1, 1:2, $1: 4$, and $1: 8$ and assayed in duplicate to determine the linearity of this assay for tissue extracts, as well as the optimal dilution factor. For the results reported here, all pituitary extracts were measured at a dilution of 1:4 in dilution buffer. Duplicate $100 \mu \mathrm{l}$ aliquots of each standard and sample were transferred to assigned wells and incubated for $2 \mathrm{~h}$ at $37^{\circ} \mathrm{C}$. Wells were washed four times with $200 \mu \mathrm{l}$ wash buffer and $100 \mu \mathrm{l}$ tracer added to each well and incubated for $1 \mathrm{~h}$ at room temperature. Wells were washed four times and $100 \mu \mathrm{l}$ streptavidin-peroxidase conjugate added and incubated for $1 \mathrm{~h}$ at room temperature. After washing, $100 \mu \mathrm{l}$ substrate solution were added and the samples incubated for $30 \mathrm{~min}$ in the dark at room temperature. The reaction was stopped by adding $100 \mu \mathrm{l}$ stop solution. The absorbance was measured at $450 \mathrm{~nm}$. Each sample was measured in duplicate in each assay. Background measurements were made and this value subtracted from the mean value of each sample. Serum levels are reported as picogram per milliliter and pituitary values were normalized to picogram per milligram of protein. This assay had a minimum detection level of $10 \mathrm{pg} / \mathrm{ml}$ and a measurable concentration range up to $2000 \mathrm{pg} / \mathrm{ml}$. Assay of individual pituitary extracts at different dilutions showed less than $15 \%$ variability between those results that were within the measurable concentration range. When assayed at the above-mentioned dilution (1:4), all samples were within the measurable range of the standard curve. The inter- and intra-assay coefficient of variation values for repeated measure of samples were $7 \cdot 6$ and $5 \cdot 3 \%$ respectively.

\section{Immunohistochemistry}

Immunohistochemistry was performed on frozen $12 \mu \mathrm{m}$ cryostat sections, fixed in $4 \%$ paraformaldehyde $(20 \mathrm{~min}$, room temperature), washed in TBS $+0 \cdot 1 \% \mathrm{BSA}$ and $0 \cdot 1 \%$ Triton X-100 (this buffer was used for all subsequent washes), and blocked in TBS containing 3\% BSA and 1\%
Triton X-100 for $2 \mathrm{~h}$. For immunofluorescence, sections were left overnight in a humid chamber at $4{ }^{\circ} \mathrm{C}$ with the primary antibodies for prolactin $(1: 2000)$ plus $\mathrm{H} 3$ (1:100) in blocking solution. Afterwards, the sections were washed and incubated with a biotin-conjugated anti-rabbit (Pierce; 1:1000) and an anti-guinea pig antibody conjugated to Alexa Fluor 488 (Molecular Probes, Eugene, OR, USA; 1:2000) for $90 \mathrm{~min}$. After washing $(3 \times 20 \mathrm{~min}$ each), sections were then incubated in streptavidin-Alexa Fluor 633 conjugate (Molecular Probes, 1:2000) for $1 \mathrm{~h}$. After the addition of the Alexa fluorochromes, all incubations were carried out in the dark. The resulting signal was visualized by using a confocal microscope (Leica, Madrid, Spain).

For double labeling of BrdU and prolactin, the sections were fixed in $4 \%$ paraformaldehyde (in $0.1 \mathrm{M}$ PBS) for $20 \mathrm{~min}$ at room temperature and then washed in PBS $(3 \times$ $15 \mathrm{~min}$ each). The sections were incubated with $1 \%$ hydrogen peroxide in 100\% methanol for $20 \mathrm{~min}$, washed twice for $20 \mathrm{~min}$ in PBS, incubated in $2 \mathrm{M} \mathrm{HCl}$ for $30 \mathrm{~min}$, and washed in PBS twice for $20 \mathrm{~min}$ each. Afterwards, sections were blocked in TBS buffer with 3\% BSA and 1\% Triton X-100. This buffer was used in the following washes and incubations. The sections were incubated overnight at $4{ }^{\circ} \mathrm{C}$ with the primary antibodies, PRL (1:2000) and BrdU (1:100). The following day, sections were washed and incubated with a biotin-conjugated anti-mouse antibody and an anti-guinea pig antibody conjugated to HRP (Pierce, 1:1000) for $90 \mathrm{~min}$. Peroxidase and biotin activities were revealed, using $3,3^{\prime}$-diaminobenzine with $0 \cdot 01 \%$ hydrogen peroxide and 4-nitroblue tetrazolium chloride, 5-bromo-4chloro-3-indolyl-phosphate toluidine (Roche Diagnostic) as chromogens. Immunostained sections were observed by optical microscopy (Zeiss Axioplan, Germany).

Concentration curves were performed to determine the appropriate concentration of primary antibodies. In all immunohistochemistry assays, omission of primary antibody resulted in no specific labeling.

\section{Statistical analysis}

All results were performed at least two times. All results were reported as mean \pm s.E.M. All western-blot results were normalized to actin levels in the same sample and then to mean control levels in each assay (control $=100 \%$ ). One-way ANOVA was used for comparisons between groups, followed by a Scheffe's F-test. Significance was chosen as $P<0 \cdot 05$.

\section{Results}

\section{Serum glucose concentrations}

At the time of death, glucose concentrations in all STZtreated groups were higher than in the control group 
Table 1 Plasma glucose concentrations in control and diabetic rats. Results are mean \pm S.E.M. $n=4$ for each diabetic group and $n=8$ for controls

Glucose concentrations $(\mathrm{mg} / \mathrm{dl})$

Control

DB1W

DB4W

DB6W

DB8W

\section{Intracellular prolactin levels}

Total prolactin levels per pituitary decreased throughout the study, becoming significantly lower than controls at 6 weeks (Fig. 1B; ANOVA: $P<0 \cdot 01$ ).

\section{Caspase- 8 activation in the anterior pituitary}

The fragmented form of caspase- 8 was significantly higher in pituitaries of DB4W and DB8W compared with controls (Fig. 2; ANOVA: $P<0 \cdot 01$ ), while the proform increased significantly at 8 weeks of diabetes (ANOVA: $P<0 \cdot 002$ ).

*ANOVA: $P<0 \cdot 001$. DB1W, 1 week of diabetes; DB4W, 4 weeks of diabetes; DB6W, 6 weeks of diabetes; DB8W, 8 weeks of diabetes.

$(P<0 \cdot 001)$ with no difference between the diabetic groups (Table 1).

\section{Pituitary cell death}

Mean cell death, as determined by ELISA for histones, was significantly increased in the pituitary of diabetic rats compared with controls 4 weeks after the onset of diabetes and increased further during weeks 6 and 8 (Fig. 1A; ANOVA: $P<0 \cdot 001$ ).
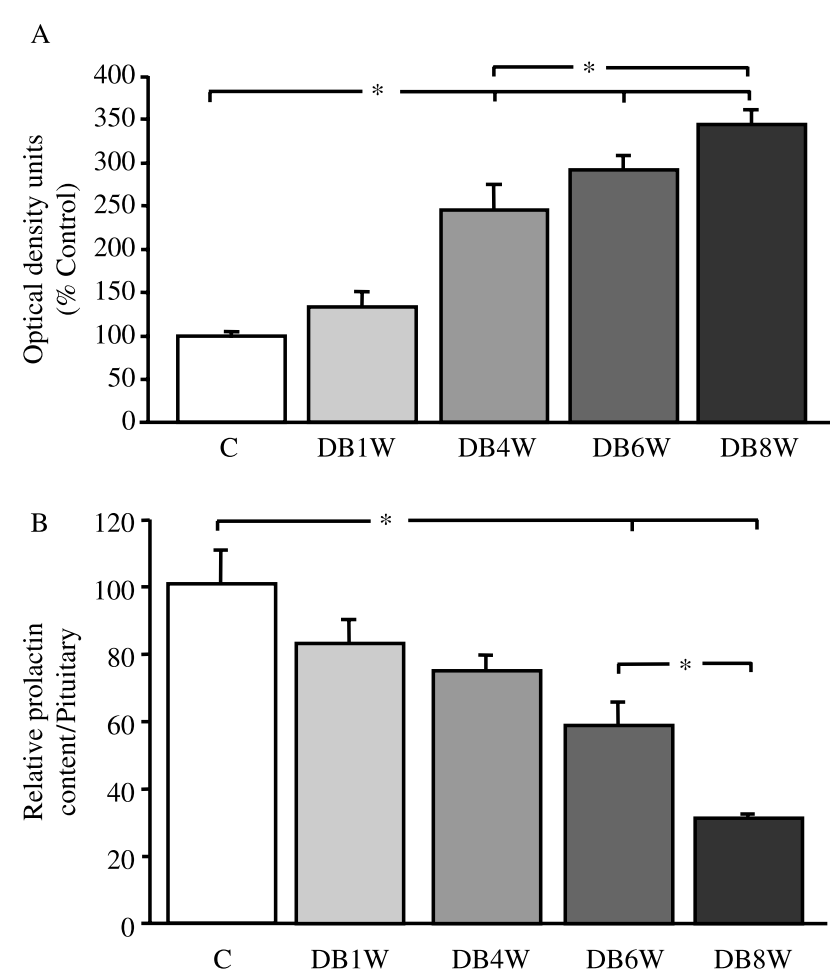

Figure 1 (A) Relative levels of cell death in the pituitary of diabetic rats as determined by ELISA. *ANOVA: $P<0 \cdot 001$. (B) Mean total prolactin levels per pituitary in control and diabetic rats. ${ }^{*}$ ANOVA: $P<0 \cdot 001$. C, control; DB1W, 1 week of diabetes; DB4W, 4 weeks of diabetes; DB6W, 6 weeks of diabetes; DB8W, 8 weeks of diabetes. Results are mean \pm s.E.M. $n=4$ for each diabetic group and $n=8$ for controls.

\section{TNF- $\alpha$ levels}

Serum TNF- $\alpha$ levels were significantly elevated compared with controls throughout the study. However, at 6 weeks there was a significant decrease in circulating TNF- $\alpha$ levels, which rose again at 8 weeks of diabetes evolution (Fig. 3A; ANOVA: $P<0 \cdot 0001)$.

$\mathrm{TNF}-\alpha$ protein levels in the anterior pituitary were not significantly modified until after 8 weeks of diabetes, when there was a significant increase (Fig. 3B; ANOVA: $P<0 \cdot 001$ ).

\section{Proliferation}

Western-blot analysis showed a significant decrease in relative PCNA levels 1 week after streptozotocin treatment that returned to control levels at 4 and 6 weeks and increased significantly at 8 weeks of diabetes (Fig. 4; ANOVA: $P<0 \cdot 01$ ).

This increase in proliferation was confirmed by immunostaining for phospho-H3. The number of phospho-H3 positive cells was greater in the anterior pituitary of diabetic animals compared with controls after 8 weeks of diabetes, but not at 6 weeks (Fig. 5A-C). No colocalization of H3 with prolactin, growth hormone, thyroid stimulating hormone, luteinizing hormone, or adrenocorticotropic hormone was found (data not shown).

Fewer BrdU immunostained cells (dark blue) were found in control (Fig. 5D) compared with DB8W pituitaries (Fig. 5E). Cells immunostained for BrdU could be found to colocalize with prolactin immunostaining (brown; Fig. 5E, solid arrows). Although the majority of BrdU positive cells coexpressed prolactin, some did not (Fig. 5D and E, hollow arrows).

\section{Discussion}

Cell turnover in the anterior pituitary can be altered by different events, including poorly controlled diabetes mellitus. We previously reported that at 8 weeks of diabetes evolution lactotrophs undergo increased cell death, most likely through activation of caspase-8 (Arroba et al. 2003, 2005). Here, we show that after 1 week of diabetes pituitary cell death is not significantly modified, but by 4 weeks a significant increase in cell death is detected and this 


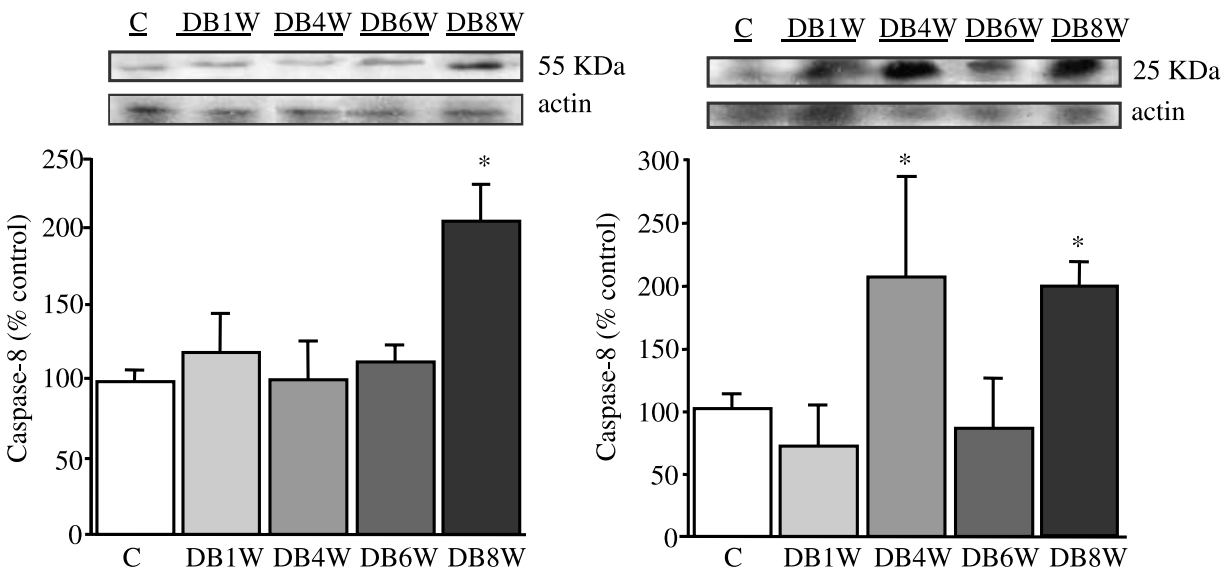

Figure 2 (A) Relative levels of the intact $55 \mathrm{kDa}$ form of caspase-8 in the pituitary of control and diabetic rats. ANOVA: $P<0 \cdot 002$. *Significant difference compared with controls. (B) Relative levels of the cleaved $25 \mathrm{kDa}$ form of caspase- 8 in the pituitaries of control and diabetic rats. ANOVA: $P<0 \cdot 01$. *Significant difference compared with controls. C, control; DB1W, 1 week of diabetes; DB4W, 4 weeks of diabetes; DB6W, 6 weeks of diabetes; DB8W, 8 weeks of diabetes. Results are mean \pm s.E.M. $n=4$ for each diabetic group and $n=8$ for controls.

continued to increase throughout the 8 weeks of study. The decline in intracellular prolactin levels temporally parallels these changes, suggesting that the loss of lactotrophs is involved in the decrease in circulating prolactin levels. It is possible that there is also a decrease in prolactin synthesis per lactotroph, although previous reports suggest that this is not the case (Boujon et al. 1995).

The increase in cell death at 4 weeks of diabetes is coincident with increased activation of caspase-8; however, although cell death continues to be increased at 6 weeks, activation of caspase- 8 decreases at this time-point, and then rises again at 8 weeks. It is possible that more than one mechanism of cell death is involved, although we are unable to detect activation of the intrinsic cell death pathway or downstream effector caspases-3, -6 , or -7 after 8 weeks of diabetes (Arroba et al. 2005) or earlier during the evolution of diabetes (unpublished observation).

Circulating TNF- $\alpha$ levels have previously been reported to be elevated in diabetic patients and streptozotocininduced diabetic rats (El-Seweidy et al. 2002, Jain et al. 2002) and this cytokine is implicated in activation of the extrinsic cell death pathway (Gupta 2001), apoptosis during diabetes (Chen \& Goeddel 2002), and apoptosis of lactotrophs (Candolfi et al. 2002). However, circulating TNF- $\alpha$ levels were increased as early as 1 week after the onset of diabetes, while caspase- 8 activation and increased cell death was not detected until the fourth week. It is possible that there is a delayed response to TNF- $\alpha$ as has been shown in other paradigms (Augstein et al. 2004, Jaita et al. 2005). Circulating TNF- $\alpha$ levels and activation of caspase- 8 both decreased significantly at 6 weeks and increased at 8 weeks, suggesting that they may be correlated, although a direct relationship cannot be established from these studies. The underlying cause of these dynamic changes is not apparent. In the diabetic rats, there was no change in mean glucose levels at any time throughout the study, suggesting that a change in glucose metabolism is not responsible for the inflection in the elevated levels of circulating TNF- $\alpha$ at 6 weeks. Furthermore, although body weight and weight gain of diabetic rats were reduced compared with controls, these parameters were stabilized in the diabetic rats at this moment of the study and cannot explain the changes in circulating TNF- $\alpha$ levels.

In the pituitary, TNF- $\alpha$ is produced by macrophages, as well as by somatotrophs, while lactotrophs do not appear to synthesize this cytokine (Arras et al. 1996). Pituitary TNF- $\alpha$ levels were not increased until after 8 weeks of diabetes, and hence, cannot account for the increase in caspase- 8 activation at 4 weeks, although it is possible that the second rise in caspase- 8 activation at 8 weeks could be related to the increase in local TNF- $\alpha$. Local production of this cytokine is suggested to be a stress response (Kariagina et al. 2004) and this delayed increase in local TNF- $\alpha$ concentrations could indicate that this gland has reached a critical moment in response to the chronic poor metabolic control.

We previously reported an increase in PCNA levels in the rat pituitary after 8 weeks of diabetes (Arroba et al. 2003). We hypothesized that this increase in proliferation could be in response to the increased cell death in an attempt to maintain the cell population. This would suggest that proliferation should occur either simultaneously or after cell death has increased. Indeed, all markers of cellular proliferation, PCNA, phosphorylated histone-H3 and BrdU incorporation, were increased only after 8 weeks of diabetes, while significant cell death was detected as early as 4 weeks. In addition, this increase in proliferation was found to affect 


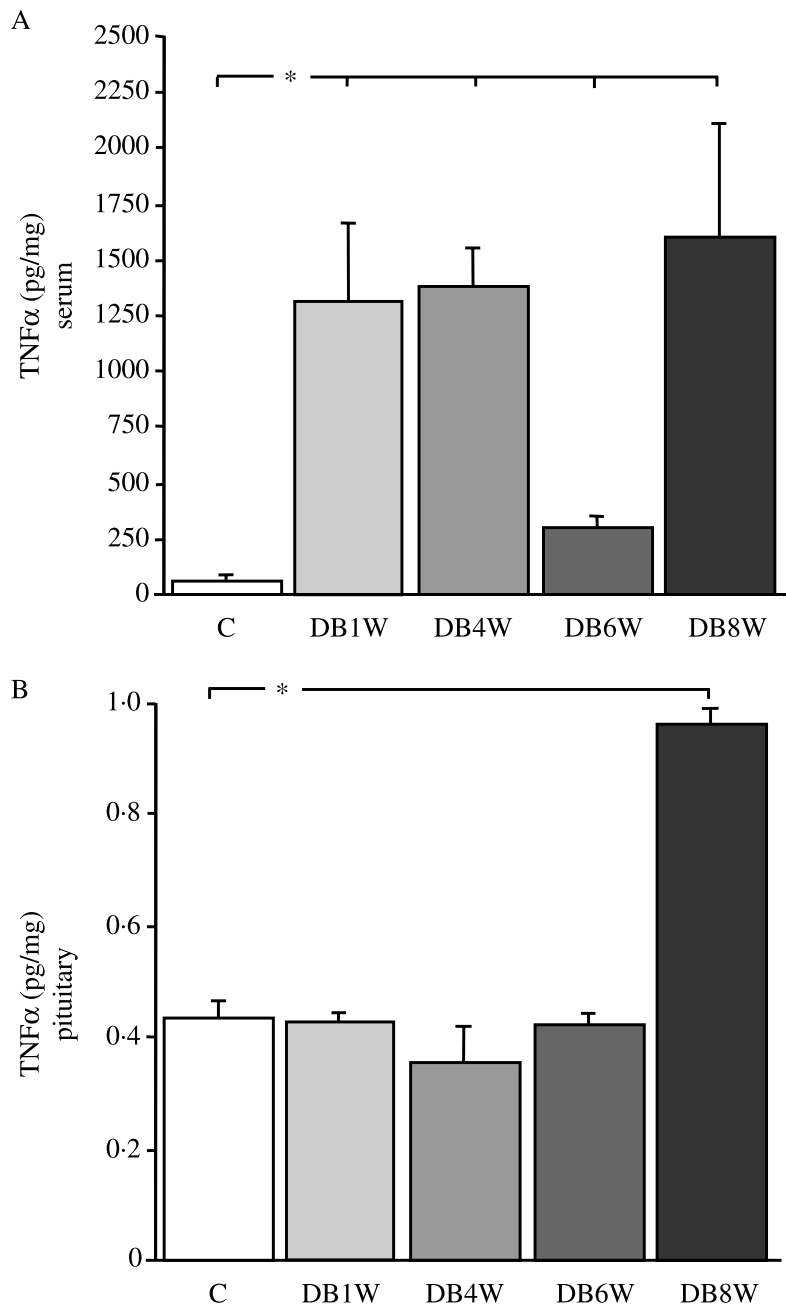

Figure 3 Mean levels of (A) TNF- $\alpha$ in serum (*ANOVA: $P<0 \cdot 0001)$ and $(B)$ the anterior pituitary (*ANOVA: $P<0 \cdot 001)$ of control and diabetic rats. C, control; DB1W, diabetic for 1 week; DB4W, diabetic for 4 weeks; DB6W, diabetic for 6 weeks; DB8W, diabetic for 8 weeks. Results are mean \pm S.E.M. $n=4$ for each diabetic group and $n=8$ for controls.

lactotrophs, the cell type most affected by the increase in cell death. Phosphorylated histone-H3 immunoreactivity did not colocalize with any anterior pituitary hormone. This is most likely due to the fact that this marker of mitosis labels cells that were dividing at the moment of death of the animal and at this stage of the cell cycle secreted hormones are not yet expressed. In contrast, BrdU is detected in cells that divided after BrdU injection, which in this study is up to 4 days prior to being processed. This would allow time for cell differentiation and hormone expression, allowing identification of proliferating cell types.

Cell turnover in the normal adult anterior pituitary is influenced by physiological signals including age, sex, and a variety of hormones (Takahashi \& Kawashima 1982,

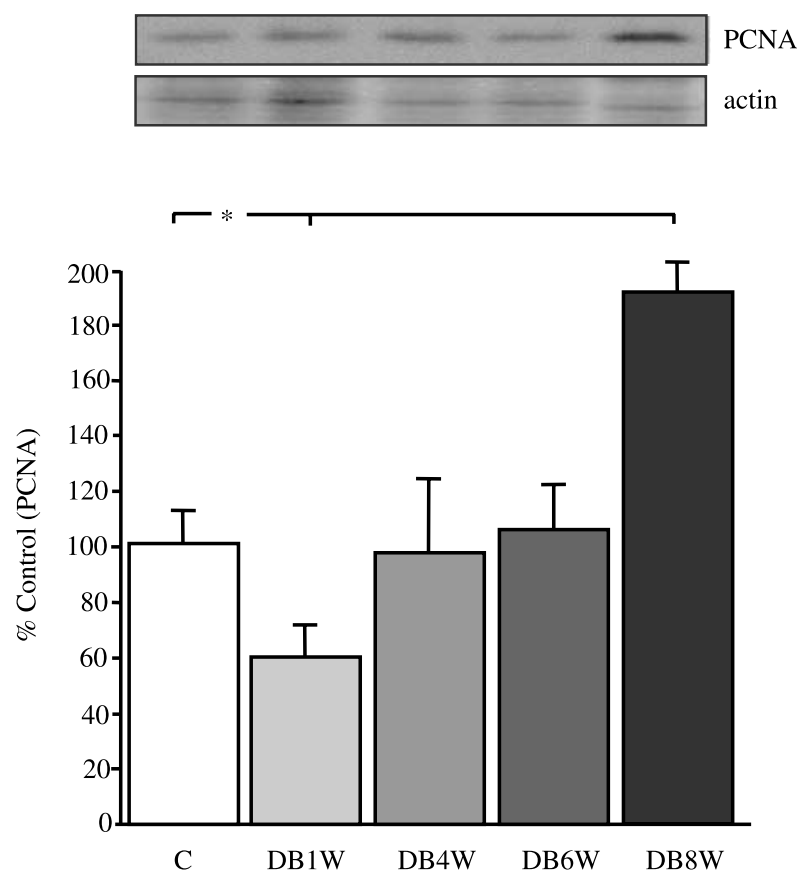

Figure 4 Mean levels of proliferating cell nuclear antigen (PCNA) in the anterior pituitary of control and diabetic rats at different times of diabetes evolution as measured by western blot. ANOVA: $P<0 \cdot 01$. C, control; DB1W, diabetic for 1 week; DB4W, diabetic for 4 weeks; DB6W, diabetic for 6 weeks; DB8W, diabetic for 8 weeks. Results are mean \pm S.E.M. $n=4$ for each diabetic group and $n=8$ for controls.

Hoeffler \& Frawley 1987, Carbajo-Pérez \& Watanabe 1990, Ellerkmann et al. 1991, Kineman et al. 1992, Oishi et al. 1993, Kulig et al. 1998, Nolan et al. 1998). Changes in the balance of these signals can modify the cellular make-up of the anterior pituitary, with lactotrophs being one of the most highly affected cell types (Takahashi \& Kawashima 1982, Hoeffler \& Frawley 1987, Ellerkmann et al. 1991, Kineman et al. 1992, Oishi et al. 1993). One of the most clear examples is the dramatic increase in lactotroph proliferation during pregnancy and lactation (Goluboff \& Ezrin 1969), followed by massive cell death at the termination of pregnancy or lactation (Haggi et al. 1986, Ahlbom et al. 1998). The increase in lactotroph cell death upon weaning has been associated with changes in Bax, Bcl2, and p53 expression (Ahlbom et al. 1998). The Bcl-2 family of proteins is also involved in estrogen and thyroid hormone modulation of lactotroph turnover (Kulig et al. 1998), while bromocryptine, a dopamine antagonist, induced death of lactotrophs involves p53 (Aoki et al. 2001). Thus, physiological turnover of lactotrophs appears to involve the mitochondrial/intrinsic intracellular pathway.

However, little is known regarding pituitary cell death in pathological situations. Nitric oxide-induced pituitary cell death is reported to involve activation of caspases-3 and -9 (Velardez et al. 2004), but whether this involves lactotrophs 

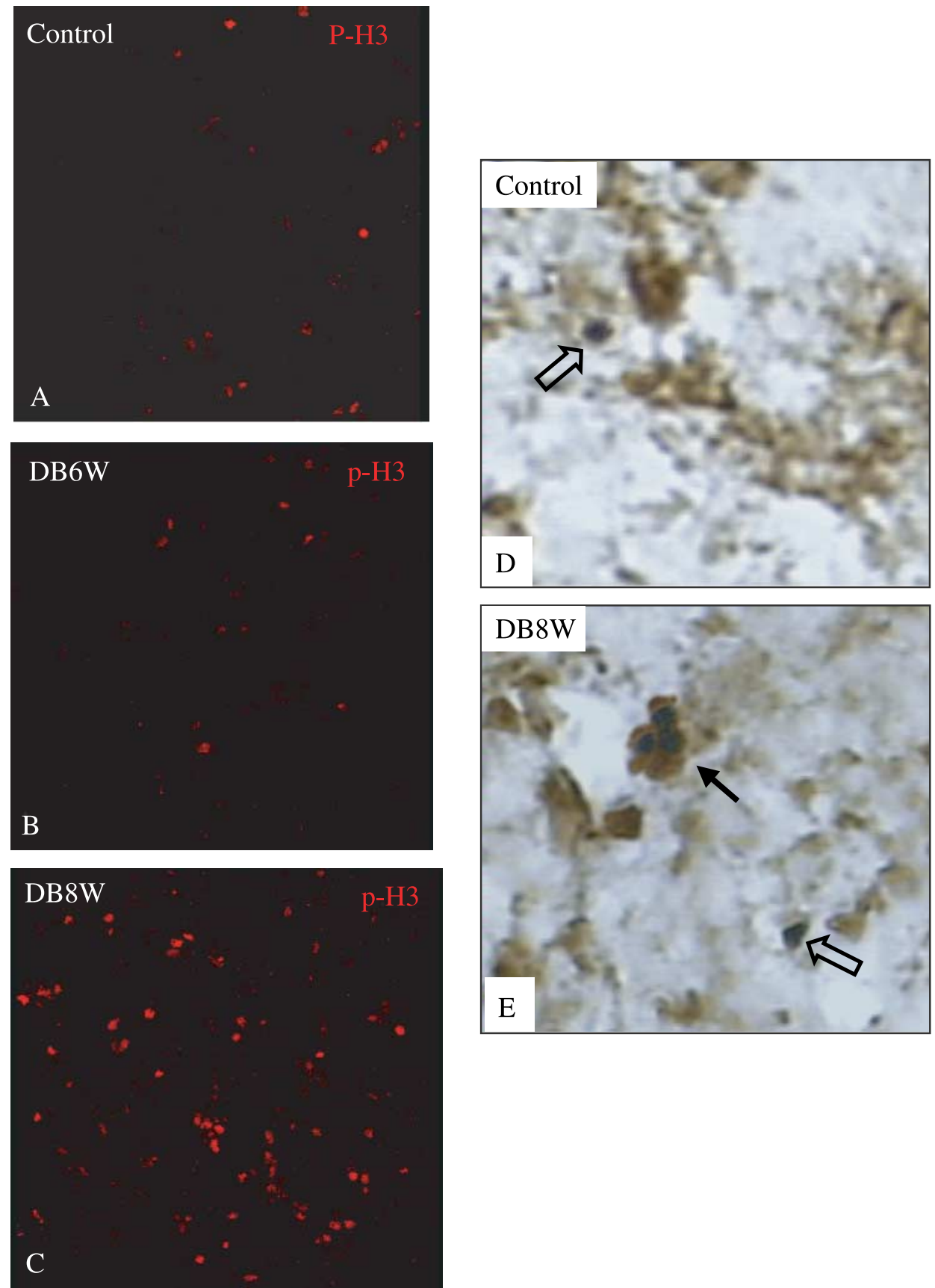

Figure 5 Immunohistochemistry for phosphorylated histone $3(\mathrm{p}-\mathrm{H} 3)$ to label mitotic cells in the anterior pituitary of (A) control rats and (B) rats that were diabetic for 6 weeks and (C) 8 weeks. Increased labeling was seen only at 8 weeks of diabetes evolution. $n=3$ in each experimental group. Immunolabeling for $\mathrm{BrdU}$ (blue) and prolactin (brown) in (D) control, and (E) diabetic rats that were injected with BrdU on 4 consecutive days prior to death after 8 weeks of diabetes showed that there was an increase in proliferating cells in the diabetic rats. The majority of the BrdU positive cells were immunopositive for prolactin. Solid arrows indicate cells that were positive for both BrdU and prolactin. Hollow arrows indicate BrdU positive cells. $n=4$ in each experimental group. 
remains to be determined. In contrast to physiological situations of anterior pituitary cell turnover, diabetes induced lactotroph cell death appears to involve the extrinsic cell death pathway and activation of caspase-8. Increased levels of TNF$\alpha$ may be involved as this cytokine has been shown to induce apoptosis of lactotrophs (Candolfi et al. 2002).

The results reported here demonstrate that cell death in the anterior pituitary begins as early as 1 month after the onset of diabetes, involving activation of caspase-8. A delayed increase in proliferation occurs after 8 weeks of diabetes and affects primarily lactotrophs, indicating that the rise in proliferation is specific to the cell type undergoing increased death. The underlying cause of these changes and whether insulin treatment can prevent or reverse these modifications remains unknown. However, it is clear that between 4 and 8 weeks of diabetes evolution there is a critical period when dynamic changes in anterior pituitary cell turnover occur and that lactotrophs are highly affected.

\section{Funding}

This work was funded by grants from Fondo de Investigación Sanitaria (PI04/0817 and PI051268), Ministerio de Educación (SAF2002-03324), Fundación de Investigación Médica Mutua Madrileña, and Fundación de Endocrinología y Nutrición. A M L S is supported by a post-medical training fellowship from Fondo de Investigación Sanitaria. J A C is supported by the Biomedical Investigation program of the Consejería de Sanidad $y$ Consumo de la Comunidad de Madrid. The authors verify that there is no conflict of interest that would prejudice the impartiality of these studies.

\section{References}

Ahlbom E, Grandison L, Zhivotovsky B \& Ceccatelli S 1998 Termination of lactation induces apoptosis and alters the expression of the Bcl-2 family members in the rat anterior pituitary. Endocrinology 139 2465-2471.

Aoki MP, Aoki A \& Maldonado CA 2001 Sexual dimorphism of apoptosis in lactotrophs induced by bromocryptine. Histochemistry and Cell Biology 116 215-222.

Arras M, Höche A, Bohle R, Eckert P, Riedel W \& Schaper J 1996 Tumor necrosis factor- $\alpha$ in macrophages of heart, liver, kidney, and in the pituitary gland. Cell and Tissue Research 285 39-49.

Arroba AI, Frago LM, Pañeda C, Argente J \& Chowen JA 2003 The number of lactotrophs is reduced in the anterior pituitary of streptozotocin-induced diabetic rats. Diabetologia 46 634-638.

Arroba AI, Frago LM, Argente J \& Chowen JA 2005 Activation of caspase 8 in the pituitaries of streptozotocin-induced diabetic rats: implication in increased apoptosis of lactotrophs. Endocrinology 146 4417-4424.

Augstein P, Heinke P, Salzsieder E, Berg S, Rettig R, Salzsieder C \& Harrison LC 2004 Fas ligand down-regulates cytokine-induced Fas receptor expression on insulinoma (NIT-1), but not islet cells, from autoimmune nonobese diabetic mice. Endocrinology 145 2747-2752.

Boldin MP, Goncharov TM, Goltsev YV \& Wallach D 1996 Involvement of $\mathrm{MACH}$, a novel MORT1/FADD-interacting protease, in Fas/APO-1- and TNF receptor-induced cell death. Cell 85 803-815.
Bole-Feysot C, Goffin V, Edery M, Binart N \& Kelly PA 1998 Prolactin (PRL) and its receptor: actions, signal transduction pathways and phenotypes observed in PRL receptor knockout mice. Endocrine Reviews 19 225-268.

Boujon CE, Besteti GE, Abramo F, Locatelli V \& Rossi GL 1995 The reduction of circulating growth hormone and prolactin in streptozotocininduced diabetic male rats is possibly caused by hypothalamic rather than pituitary changes. Journal of Endocrinology 145 19-26.

Candolfi M, Zaldivar V, De Laurentiis A, Jaita G, Pisera D \& Seilicovich A 2002 TNF-alpha induces apoptosis of lactotropes from female rats. Endocrinology 143 3611-3617.

Carbajo-Pérez E \& Watanabe YG 1990 Cellular proliferation in the anterior pituitary of the rat during the postnatal period. Cell and Tissue Research $\mathbf{2 6 1}$ 333-338.

Chen G \& Goeddel DV 2002 TNF-R1 signaling: a beautiful pathway. Science 296 1634-1635.

Ellerkmann E, Nagy GM \& Frawley LS 1991 Rapid augmentation of prolactin cell number and secretory capacity by an estrogen-induced factor released from the neurointermediate lobe. Endocrinology 129 838-842.

El-Seweidy MM, El-Swefy SE, Ameen RS \& Hashem RM 2002 Effect of age receptor blocker and/or anti-inflammatory coadministration in relation to glycation, oxidative stress and cytokine production in STZ diabetic rats. Pharmacological Research 45 391-398.

Goluboff LG \& Ezrin C 1969 Effect of pregnancy on the somatotrophs and the prolactin cell of the human adenohypophysis. Journal of Clinical Endocrinology and Metabolism 29 1533-1538.

Gupta S 2001 Molecular steps of death receptor and mitochondrial pathways of apoptosis. Life Sciences 69 2957-2964.

Haggi ES, Torres AI, Maldonado CA \& Aoki A 1986 Regression of redundant lactotrophs in rat pituitary gland after cessation of lactation. Endocrinology $\mathbf{1 1}$ 367-373.

Hoeffler JP \& Frawley LS 1987 Hypothalamic factors differentially affect the proportions of cells that secrete growth hormone or prolactin. Endocrinology $120791-795$.

Ikawa H, Irahara M, Matsuzaki T, Saito S, Sano T \& Aono T 1992 Impaired induction of prolactin secretion from the anterior pituitary by suckling in streptozotocin-induced diabetic rat. Acta Endocrinologica 126 167-172.

Jain SK, Kannan K, Lim G, McVie R \& Bocchini JA Jr 2002 Hyperketonemia increases tumor necrosis factor-alpha secretion in cultured U937 monocytes and type 1 diabetic patients and is apparently mediated by oxidative stress and cAMP deficiency. Diabetes 51 2287-2293.

Jaita G, Candolfi M, Zaldivar V, Zárate S, Ferrari L, Pisera D, Castro MG \& Seilicovich A 2005 Estrogens up-regulate the Fas/FasL apoptotic pathway in lactotropes. Endocrinology 146 4737-4744.

Kariagina A, Romanenko D, Ren SG \& Chesnokova V 2004 Hypothalamicpituitary cytokine network. Endocrinology 145 104-112.

Kineman RD, Faught WJ \& Frawley LS 1992 Steroids can modulate transdifferentiation of prolactin and growth hormone cells in bovine pituitary cultures. Endocrinology 130 3289-3296.

Kinsley BT, Levy CJ \& Simonson DC 1996 Prolactin and beta-endorphin responses to hypoglycemia are reduced in well-controlled insulindependent diabetes mellitus. Metabolism 45 1434-1440.

Kulig E, Camper SA, Kuecker S, Jin L \& Lloyd RV 1998 Remodeling of hyperplastic pituitaries in hypothyroid us-subunit knockout mice after thyroxine and $17 \beta$-estradiol treatment: role of apoptosis. Endocrine Pathology 9 261-274.

Lau C, Sullivan MK \& Hazelwood RL 1993 Effects of diabetes mellitus on lactation in the rat. Proceedings of the Society for Experimental Biology and Medicine 204 81-89.

Montelongo A, Lasuncion MA, Pallardo LF \& Herrera E 1992 Longitudinal study of plasma lipoproteins and hormones during pregnancy in normal and diabetic women. Diabetes 41 1651-1659.

Neville MC \& Morton J 2001 Physiology and endocrine changes underlying human lactogenesis II. Journal of Nutrition 131 3005S-3008S.

Nolan LA, Kavanagh E, Lightman SL \& Levy A 1998 Anterior pituitary cell population control: basal cell turnover and the effects of adrenalectomy and dexamethasone treatment. Journal of Neuroendocrinology 10 2007-2015. 
Oishi Y, Okuda M, Takahashi H, Fujii T \& Morii S 1993 Cellular proliferation in the anterior pituitary gland of normal adult rats: influences of sex, estrous cycle, and circadian change. Anatomical Record 235 111-120.

Ostrom KM \& Ferris AM 1993 Prolactin concentrations in serum and milk of mothers with and without insulin-dependent diabetes mellitus. American Journal of Clinical Nutrition 58 49-53.

Ratner A, Pasternack LB \& Weiss GK 1991 Effect of restraint stress on prolactin and corticosterone levels in streptozotocin-induced diabetic rats. Life Sciences 48 887-891.

Sudha S, Sankar BR, Valli G, Govindarajulu P \& Balasubramanian K 1999 Streptozotocin-diabetes impairs prolactin binding to Leydig cells in prepubertal and pubertal rats. Hormone and Metabolic Research 31 583-586.

Takahashi S \& Kawashima S 1982 Age-related changes in prolactin cell percentage and serum prolactin levels in intact and neonatally gonadectomized male and female rats. Acta Anatomica 113 211-217.
Valimaki M, Liewendahl K, Nikkanen P \& Pelkonen R 1991 Hormonal changes in severely uncontrolled type 1 (insulin-dependent) diabetes mellitus. Scandinavian Journal of Clinical and Laboratory Investigation 51 385-393.

Velardez MO, Poliandri AH, Cabilla JP, Bodo CC, Machiavelli LI \& Duvilanski BH 2004 Long-term treatment of anterior pituitary cells with nitric oxide induces programmed cell death. Endocrinology 145 2064-2070.

Wajant H 2002 The Fas signaling pathway: more than a paradigm. Science $\mathbf{2 9 6}$ $1635-1636$.

Received 6 April 2006

Received in final form 21 June 2006

Accepted 27 June 2006

Made available online as an Accepted Preprint 1 August 2006 